\title{
巴黎协定下中国碳排放权省域分配及 减排潜力评估研究
}

\author{
田云, 林子娟 \\ (中南财经政法大学工商管理学院,武汉 430073)
}

\begin{abstract}
摘要：通过构建碳排放权区域分配模型完成了省域分配, 在此基础上与当前各地实际碳排放 量进行比对, 明晰了各自初始空间余额; 而后对碳排放权欠缺地区的碳减排潜力进行了综合评 估。研究结果表明: (1) 我国 30 个省区碳排放权分配存在较大差异, 其中云南配额最高, 占比高 达 $10.53 \%$; 宁夏配额最少, 占比仅为 $0.28 \%$ 。(2) 全国有 14 个省区碳排放权初始空间余额表现出 盈余状态 , 根据成因差异可大致分为 “低排放、高配额” “低排放、低配额”以及 “高排放、高配额” 等三种类型; 其他 16 个地区均表现出一定程度的欠缺, 结合数值差异可划分为以江苏等 4 地为 代表的轻度欠缺地区, 以天津等 7 地为代表的中度欠缺地区, 以及以辽宁等 5 地为代表的重度 欠缺地区。(3)浙江、天津、山东等 3 地目前所具备的碳减排潜力要明显高于其他地区, 而各地区 的碳减排潜力水平虽与其碳排放权欠缺量表现出了一定趋同性但并非完全一致。
\end{abstract}

关键词：碳排放;农业碳排放;碳排放权;省域分配;减排潜力

近年来，由二氧化碳等温室气体排放所导致的气候变暖对全球生态环境带来了极大 破坏，同时也在一定程度上加剧了疾病传播。一系列不利影响的出现使得国际社会逐步 认识到，气候问题已不属于区域性问题，更不是某一个国家或地区所能解决的，而是世 界各国必须共同应对的全球性问题。为了有效应对全球气候变化所带来的一系列挑战， 各国相继达成了《联合国气候框架公约》等 3 个具有较强国际影响力的协定。其中，于 2015年 12 月达成、并于 2016年 4 月正式签署的《巴黎协定》从控制气温上升幅度、提高 各行业适应气候变化能力、使资金流动符合低碳经济发展导向等三个方面确立了全球应 对气候变化威胁的总目标。而之后相继召开的马拉喀什、波恩以及卡托维兹气候会议 上, 各缔约方则就《巴黎协定》的具体实践路径达成了基本一致。作为全球气候治理的 重要参与者, 中国早在《巴黎协定》签订之前就已向世界各国公布了未来的减排计划。 为了尽早实现这一减排目标并完成美丽中国建设的伟大愿景, 今后应切实加快温室气体 减排步伐。

有鉴于减排工作重要性的不断凸现，近年来有不少学者立足于中国碳排放问题展开 深度探讨, 并形成了较为丰硕的研究成果。其中, 早期研究主要围绕碳减排成本的国际 比较 ${ }^{[1]}$ 、减排目标约束下的历史责任梳理与排放配额探讨 ${ }^{[2,3]}$ 、人文发展对碳排放空间需求 的理论阐述 ${ }^{[4]}$ 等几个方面，总体聚焦于理论和政策分析，但在一定程度上缺乏对碳排放现

收稿日期：2019-12-04；修订日期：2020-03-17

基金项目：国家自然科学基金项目（71903197); 湖北省社会科学基金项目（2019052); 中南财经政法大学中央高校 基本科研业务费专项资金资助项目（2722020JCT020）

作者简介: 田云 (1986-), 男, 湖北长阳人, 博士, 副教授, 研究方向为资源与环境经济, 低碳经济与低碳农业。 E-mail: tianyun1986@163.com 
状特征与内在机理的系统剖析。而后, 随着相关研究的不断深人, 学者们的视角选择越 发细致，并形成了大量能反映我国碳排放现状与特征的研究成果，同时在减排问题的 探索上也取得了一定进展。相关成果主要聚焦于三个方面：一是碳排放测算与基本特 征分析。大多数学者根据能源消耗情况完成了对中国碳排放量的有效测度同时分析其时 空特征 ${ }^{[5,6]}$, 在此基础上或厘清其驱动机理 ${ }^{[7]}$ 、或探究其库兹涅茨曲线是否存在 ${ }^{[8]}$ 。与此同 时, 也有学者围绕对内对外贸易中的隐含碳展开测度并分析, 如探讨中央双边贸易对二 者以及全球 $\mathrm{CO}_{2}$ 排放的影响 ${ }^{[0]}$ 、系统评估区域贸易隐含碳与污染物排放量等 ${ }^{[10]}$ 。除此之 外, 还有部分学者围绕城市能源利用 ${ }^{[1]} 、$ 农业生产部门 ${ }^{[12]}$ 等某一类碳排放展开测度并分 析。二是碳排放与经济发展的互动机理探析。为了破解节能减排与国民经济持续健康发 展之间所存在的矛盾, 一些学者开始围绕二者关系展开探讨, 结果表明, 过于追求经济 增长会加剧能源消耗与 $\mathrm{CO}_{2}$ 排放, 进而对全球气候产生不利影响 ${ }^{[13,14]}$ 。李锴等 ${ }^{\left[{ }^{[15]}\right.}$ 在探寻二 者关系时加人了贸易开放, 研究发现其导致了中国 $\mathrm{CO}_{2}$ 排放总量与强度的双增, 因此从 长远来看政府应加强环境规制。三是碳排放效率测度与减排策略研究。一些学者基于中 国 30 个主要城市以及各省级行政区的面板数据, 完成了各地区碳排放效率、减排成本的 测度与比较, 结果发现, 我国碳排放效率存在明显地域差异, 总体东高西低, 而减排成 本则遵循 “先升后降” 的演变轨迹 ${ }^{[16-18]}$ 。另有些学者围绕减排路径与战略选择展开系统探 讨, 综合研究表明, 实现碳排放量减少与 GDP 增长双赢目标的关键在于能源利用效率的 提升, 而大力发展清洁能源则能起到保障作用 ${ }^{[19]}$; 除此之外, 还需注重产业与能源结构 的调整与优化, 并广泛采用各类节能减排技术、促进整体工艺水平的提升 ${ }^{[20]}$; 而在减排 政策的制定上要确保针对性，做到分类实施、动态调整与协同推进 ${ }^{[21]}$ 。

由上述文献可知, 目前关于中国碳排放问题的研究已较为系统，基本涵盖了各个 方面, 所得出的相关结论也为逐步完善我国碳排放抑或碳减排问题的研究体系奠定了 坚实基础。但同时, 现有研究也存在着一定不足, 重点体现在两个方面: 一是虽然也 有学者 $\left.{ }^{[22}\right]$ 探讨过碳排放权的省域分配问题, 但在指标体系的构建上却更倾向于各类社会 经济指标, 而忽视了以林业、农业等为代表的生态功能指标。二是在完成碳排放权省域 分配之后, 对表现出欠缺特征的地区缺少深度分析。正是基于此, 本文将重新构建碳排 放权区域分配指标体系，并以此为基础完成碳排放权的省域分配; 然后从中识别出碳排 放权初始空间余额欠缺地区并对各自碳减排潜力进行综合评估。需要说明的是, 考虑到 碳排放权的区域分配也应与国家宏观层面的减排目标相契合, 因此在后续研究中将与我 国2030年的碳强度减排目标保持高度一致。

\section{1 研究方法与数据来源}

为了实现预期研究目标，本文将采用多种分析方法。首先，通过查阅有效文献、咨 询领域内相关专家的方式完成碳排放权区域分配指标体系的构建, 并利用摘值法确定各 指标权重；同时利用 $\mathrm{k}$-均值法对 30 个省级行政区展开聚类分组。然后，在完成 20172030 年碳排放权有效测度的基础上，借助区组间碳排放权分配方法和影子价格模型实现 对 30 个省级行政区 ${ }^{\circledR}$ 碳排放权数量的分配, 并以 2017 年为例计算出各地区碳排放权的初 始空间余额, 且从中识别出盈余地区和欠缺地区。最后, 对于碳排放权欠缺地区, 科学

(1) 由于部分原始数据难以获取, 西藏、港澳台地区不在本文考察之列。 
构建评价指标体系并借助主成分分析法完成对各自碳减排潜力的综合评估。

\section{1 碳排放权区域分配指标体系构建}

\subsection{1 碳排放权区域分配指标体系确定}

已有研究表明，在碳排放权区域分配过程中，公平性和效率性原则通常扮演着较为

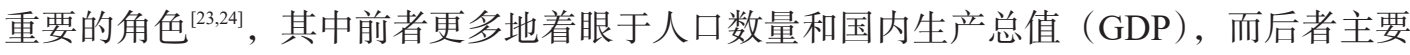
考察单位碳排放的GDP产出量。在此, 本文也将延续这一思路, 将上述二类指标纳人到 碳排放权分配指标体系的编制中。但同时，考虑到碳排放理论边界的拓展（包含农业碳 排放）以及各方对碳汇重要性认知的逐步提升, 因此在指标体系的构建上相比以往也有 所创新，具体指标构成如表 1 所示。

表 1 碳排放权分配的指标体系

Table 1 Indicator system for distribution of carbon emission rights

\begin{tabular}{cllc}
\hline & 指标 & \multicolumn{1}{c}{ 指标度量 } & 作用方向 \\
\hline 公平性 & 人口数量 & 从业劳动力数量 $/ 10^{4}$ 人 & + \\
& 国内生产总值 & GDP实际数值 $/ 10^{8}$ 元 & + \\
效率性 & 碳生产力 & GDP/碳排放量 $/($ 元 $/ \mathrm{t})$ & + \\
保障性 & 林木蓄积量 & 林木资源蓄积数量 $/ \mathrm{m}^{3}$ & + \\
& 农作物播种面积 & 农作物实际播种面积 $/ 10^{3} \mathrm{hm}^{2}$ & + \\
\hline
\end{tabular}

其中，公平性指标包含人口数量和国内生产总值，二者均为正向指标，即从业人口 数量越大、GDP 数值越高, 该地区所应分配的排放权份额理应越多。效率性指标通过碳 生产力来体现，它以实现回报最大化为目标，即期望以较少的碳排放量换取较多的期望 产出, 因此也为正向指标。而与以往研究相比, 本文增加了保障性指标, 该类指标主要 考察各地区是否拥有承受更多碳排放数量的能力，进而助推国家完成所期望的碳排放限 额要求, 具体包含林木蓄积量和农作物播种面积等两个二级指标。因为在实际生产中, 林木、农作物生长过程中所产生的光合作用能大量吸收空气中的 $\mathrm{CO}_{2}$, 起到碳抵消作 用。二者数值越大, 表明其碳吸收能力越强, 能更为有效地化解碳排放所引发的潜在危 害，故它们也属于正向指标。

\subsection{2 基于熵值法确定各指标权重}

不同于德尔菲法等过于依靠人的主观判断, 熵值法是通过各细化指标传递出来的信 息量来确定最终权重，能更为客观地揭示指标信息熵值的效用价值，从而表现出更强的 科学性。为此, 本文也将采用该方法计算各个指标的权重, 具体参照以下步骤:

首先, 消除量纲影响。定义 $x_{i j}$ 表示指标 $j$ 下 $i$ 地区数值所接近理想值的程度, 由于 本文所选择的 5 个二级指标作用方向均为正, 其理想值应为该指标的最大值 $x_{j \max }$, 故用 如下方式进行处理:

$$
\dot{x}_{i j}=\frac{x_{i j}}{x_{j \max }}
$$

通过数据标准化处理, 可得到 $\dot{x}_{i j} \quad(i=1,2, \cdots, n ; j=1,2, \cdots, m)$ 。

其次, 计算指标概率 $p_{i j}$, 公式如下: 


$$
p_{i j}=\frac{\dot{x}_{i j}}{\sum_{i=1}^{n} \dot{x}_{i j}}
$$

再者，计算第 $j$ 个指标的信息熵值 $e_{j}$, 方法见式 (3):

$$
e_{j}=\frac{\sum_{i=1}^{n} p_{i j} \ln p_{i j}}{-\ln n}
$$

然后，计算第 $j$ 个指标的信息效用值 $g_{j}$ ，方法见式 (4) :

$$
g_{j}=1-e_{j}
$$

最后，计算指标权重 $w_{j}$, 方法见式 (5):

$$
w_{j}=\frac{g_{i}}{\sum_{j=1}^{m} g_{i}}
$$

\section{$1.1 .3 k$-均值聚类分析方法}

考虑到我国各省区之间可能相似与差别并存，为此有必要将那些各方面特征相似的 地区归类聚集到同一区组，并明晰其总碳排放权; 而后再对区组内各个省区所对应的碳 排放权分配比例进行解析。鉴于此, 选取人口数量、国内生产总值、碳生产力、林木蓄 积量和农作物播种面积等 5 项指标，计算每一地区各指标 2012-2016年的年度均值并进 行标准化处理, 然后运用 $k$-均值法展开聚类分析, 从而完成对我国 30 个省级行政区的区 组划分工作。

\section{2 碳排放权测算及省区分配模型构建}

\subsection{1 碳排放权测算方法}

结合中国政府的早期承诺，本文选择 $65 \%$ 作为 2030 年碳排放强度较 2005 年所要完成 的下降目标。有鉴于此, 以2017年实际碳排放强度作为基准, 可得到碳排放强度在 2018 - 2030年间的年平均变化率 $q$ ，具体计算方式如下所示：

$$
q=1-\sqrt[13]{\frac{I_{2030}}{I_{2017}}}=1-\sqrt[13]{\frac{I_{2005} \times(1-\beta)}{I_{2017}}}
$$

式中： $\beta$ 表示中国所要实现的碳排放强度减少目标（即 65\%)； $I_{2005} 、 I_{2017} 、 I_{2030}$ 分别 表示第 2005 年、第 2017 年和第 2030 年的碳排放强度 $\left(\mathrm{kg} / 10^{4}\right.$ 元 $)$ 。

而后，对未来中国 GDP 的年均增长率进行设定，即可推算出 2018-2030年各年份的 GDP 总量。具体而言, 将以 5.00\% 6.00\%作为 GDP 预期增速, 这主要是基于现阶段我国 国民经济的发展态势来考量：统计数据揭示，2014-2018 年间我国 GDP 年平均增速为 $6.60 \%$, 从变化轨迹来看, 为了确保经济高质量发展, 增速总体处于轻微下降态势, 而未 来为了更好地促进产业结构的优化与升级, 经济增速甚至存在进一步下降的可能。同 时, 考虑到未来的不确定性, 在此选用区间增速则显得更为合理。有鉴于此, 形成了对 2018-2030 年间 GDP 预期年均增速为 5.00\% 6.00\%的基本假定。增速确定之后，结合历 年碳排放强度, 可核算出中国 2017-2030年各年的碳排放权数量。具体计算方法如式 (7) 所示:

$$
C_{t}=G D P_{2017} \times[1+(5.00 \sim 6.00) \%]^{t-2017} \times I_{2017} \times(1-q)^{t-2017}
$$


式中: $C_{t}$ 为第 $t$ 年的碳排放总量 $\left(10^{4} \mathrm{t}\right) ; G D P_{2017}$ 为 2017 年国内生产总值 $\left(10^{8}\right.$ 元 $)$ 。进 一步，可得出我国 2017-2030年碳排放权总量的计算方法如式（8）所示：

$$
C=\sum_{t=2017}^{2030} C_{t}
$$

\subsection{2 区组之间碳排放权分配方法}

基于省区聚类划分结果，可以得到各区组的组中心值，但因为不同类别指标一般不 能直接进行对比, 所以仍需对各个指标的组中心值进行计算。为此, 本文将利用已经过 无量纲化处理的原始数据，通过式（9）核算出各指标 $j$ 下的组中心。

$$
\dot{y}_{i j}=\frac{\sum_{i \in k} \dot{x}_{i j}}{n_{k}}, k=1,2, \cdots, 6
$$

式中： $n_{k}$ 表示第 $k$ 类区组所拥有的地区数量 (个)。然后, 将各项指标的权重与其对应 的组中心占比情况进行相乘，即可核算得到每一个区组的碳排放权分配比例。

\subsection{3 区组内部各省区碳排放权分配与初始空间余额测度方法}

区组内部各省级行政区碳排放权的分配将立足于碳的边际减排成本视角展开，一般 通过其影子价格来衡量。这样考虑是由碳排放权供给的稀缺性特征所决定，有限的资源 （即碳排放权）要优先保障经济效益更好的地区。影子价格越高, 意味着在特定产出条件 下, 每削减 1 个单位 $\mathrm{CO}_{2}$ 排放量所导致的 GDP 减少量越大。在此境况下, 为了确保稀缺 资源的充分利用，应将碳排放权优先分配给影子价格较高地区。具体而言，本文将借助 30 个省（市、自治区）2012-2016年的面板数据，运用基于方向性距离函数的影子价格 模型完成对各地区碳减排成本的核算，然后将其平均值作为最终的结果。其中，投人指 标为资本和劳动力，期望产出与非期望产出指标分别为 $\mathrm{GDP}$ 和 $\mathrm{CO}_{2}$ 。

模型基本假定 $x \in R_{+}^{N}$ 为投人要素，表示各省区资本与劳动力的实际投人数量; $y \in R_{+}^{M}$ 为期望产出要素, 即各省区的 GDP 数值; $c \in R_{+}^{J}$ 为非期望产出, 即各省区的 $\mathrm{CO}_{2}$ 排放数量。一般地, 方向性距离函数中需设定方向向量 $g=\left(g_{v}, g_{c}\right)$ 且 $g \in R_{+}^{M} \times R_{+}^{J}$, 用于 限定各产出指标的变动方向与大小, 而方向向量的选择相对灵活, 可依据自身研究所需 进行设定, 具体到本文则取 $g=(1,-1)$ 。基于产出径向的方向性距离函数可以表示如下:

$$
D(x, y, c, 1,-1)=\max \left\{a:\left(y+a^{*} 1, c+a^{*}(-1)\right) \in P(x)\right\}
$$

式中： $a$ 表示在投人要素不被增加的条件下期望产出所能实现的最大提升比例; $P(x)$ 表 示基于环境技术条件支持下的一切可能生产集合。

根据环境技术规定的期望与非期望产出的联合弱可处置性，在生产可能性集合 $P(x)$ 内, 降低 $\mathrm{CO}_{2}$ 排放量会直接引致 GDP 数值的减少, 即环境管制对期望产出的边际 效应 ${ }^{[23]}$ 。为此, 结合二者的数值变化就可得到碳的影子价格, 其计算公式如下:

$$
p_{c}=p_{y} \times \frac{\partial D(x, y, c, 1,-1) / \partial c}{\partial D(x, y, c, 1,-1) / \partial y}
$$

式中: $p_{y}$ 表示 $\mathrm{GDP}$ 的价格 $\left(10^{4}\right.$ 元)； $p_{c}$ 代表 $\mathrm{CO}_{2}$ 的影子价格（元/t), 即碳边际减排成 本。接下来，基于区组内碳减排成本的不同完成对各省级行政区碳排放权分配比例 $C$ 的核算，具体计算公式如下:

$$
C=\frac{p_{c}}{\sum_{i \in k} p_{c}}, k=1,2, \cdots, 6
$$


而后, 由分配比例并结合各区组的碳排放权分配数量即可确定各地区的实际分配数 额。在此基础上, 将各地区 2017 年理论碳排放权分配额与其实际碳排放量相减, 所得差 额即为 30 个地区在该年的碳排放权初始空间余额。如果差值为正，表明该地区存在碳排 放权盈余，客观上分担了其他地区多余的碳排放；相反则表明碳排放权处于欠缺状态， 损害了其他地区利益。

\section{3 碳排放权欠缺地区碳减排潜力综合评估方法}

\subsection{1 碳排放权欠缺地区碳减排潜力评价指标体系构建}

通过对各地区碳排放权初始空间余额进行有效测度可以识别出欠缺地区，很显然， 它们都面临着程度不一的减排压力。那么, 压力之下它们中间的哪些地区所呈现出的减 排潜力更大呢? 这仍是一个值得探讨的问题。在此，如果仅凭 “欠缺额度” 这一指标来 判断各地减排潜力显然是不够科学的, 事实上, 一个地区所能表现出来的碳减排潜力除 了与绝对欠缺数量紧密相关外，还受其减排现状、国民经济发展水平、相关政策支持等 多个因素影响。有鉴于此, 本文拟从碳排放权欠缺现状、减排现状、经济发展、政策支 持等 4 个不同维度构建综合评价指标体系，然后完成对各个碳排放权欠缺地区碳减排潜 力的有效评估。具体的细化指标选择如表 2 所示。

\section{表 2 碳排放权欠缺地区碳减排潜力评价指标体系}

Table 2 Evaluation index system of carbon emission reduction potential in areas with a lack of carbon emission rights

\begin{tabular}{|c|c|c|c|}
\hline \multicolumn{2}{|c|}{ 指标 } & \multirow{2}{*}{$\frac{\text { 指标度量 }}{\text { 碳排放权实际欠缺量 } / 10^{8} \mathrm{t}}$} & \multirow{2}{*}{$\begin{array}{c}\text { 指标方向 } \\
\text { 负向 }\end{array}$} \\
\hline 欠缺现状 & 欠缺数量 & & \\
\hline & 欠缺程度 & 碳排放权/碳排放量/\% & 正向 \\
\hline \multirow[t]{2}{*}{ 减排现状 } & 减排难度 & 碳的影子价格/(元/t) & 负向 \\
\hline & 减排效率 & 近 5 年年均减排速率/\% & 正向 \\
\hline \multirow[t]{2}{*}{ 经济发展 } & 总体水平 & GDP 总量 $/ 10^{8}$ 元 & 正向 \\
\hline & 发展程度 & GDP/总人口/(元/人) & 正向 \\
\hline \multirow[t]{2}{*}{ 政策支持 } & $\mathrm{R} \& \mathrm{D}$ 投人 & $\mathrm{R} \& \mathrm{D}$ 投人金额/GDP/\% & 正向 \\
\hline & 环境污染防治投人 & 环境污染防治投人额/GDP/\% & 正向 \\
\hline
\end{tabular}

其中, 欠缺现状由欠缺数量和欠缺程度两个细化指标构成, 前者呈现了各地当前实 际的碳排放权欠缺数量, 是其减排压力的直观体现, 数量越大通常意味着减排潜力越 小; 后者是指所分配的碳排放权与当前碳排放数量之间的比值情况，其数值越大，表明 其所分配的碳排放权接近于满足自身碳排放的需要, 减排潜力相对较高。减排现状由减 排难度和减排效率两个二级指标构成, 前者为碳的影子价格, 其数值越高, 减排所导致 的经济损失就越大，由此就会面临碳排放与经济发展之间的取舍，客观上导致了碳减排 难度的增加; 后者是指近 5 年（2012-2017年）碳排放强度的年均下降速度, 减排速率 越快, 所表现出的减排潜力必然越大。经济发展包含总体水平和发展程度两个细化指 标, 前者为 GDP 总量, 其数量越大, 表明该地综合经济实力更强, 实施节能减排的阻力 相对更小; 后者通过人均 GDP 来衡量, 通常情况下, 人均 GDP 相比 GDP 总量更能真实 地反映一个地区的社会经济发展程度，而一般经验表明，经济发展程度越高，政府所拥 有的节能减排理念就越强，给予的人力、物力以及技术支持就越多，从而表现出更强的 减排潜力, 反之则越小。政策支持由 $R \& D$ 投人和环境污染防治投人两个指标构成, 前者 
反映了一个地方对科技创新的支持力度，支持力度越大，显然会有助于节能减排技术的 研发与利用; 后者直观呈现了一个地区对防污治污的重视程度, 其所占 GDP 比例越高, 则说明该地更为重视节能减排, 减排潜力就越大。

\subsection{2 碳排放权欠缺地区碳减排潜力评估方法选择}

本文将选用主成分分析法完成对各地区碳减排潜力的评估，具体是通过几个线性组 合来解释一组变量的方差与协方差结构, 以实现对已有数据的压缩和解释。在主成分分 析中，一般基于如下思路提取综合指标：首先，设有一组指标 $x_{1} ， x_{2}, \cdots, x_{p}$, 去探 究它们的综合指标即线性组合 $F$, 并确保 $F$ 所包含的信息尽可能多, 即 $\operatorname{Var}(F)$ 达到最 大, 由此获取的 $F$ 记为 $F_{1}$; 而后继续找 $F_{2}$, 且保证 $F_{1}$ 与 $F_{2}$ 之间不存在相关性; 最 后, 重复此项操作直至找到一组综合变量 $F_{1}, F_{2}, \cdots, F_{m}$, 该组变量基本涵盖了原有 变量的所有有效信息。主成分分析法的数学模型具体如下:

设样本矩阵为:

$$
X=\left(x_{1}, x_{2}, \cdots x_{p}\right)=\left(\begin{array}{l}
x_{11}, x_{12}, \cdots, x_{1 p} \\
x_{21}, x_{12}, \cdots, x_{2 p} \\
\vdots \\
x_{n 1}, x_{n 2}, \cdots, x_{n p}
\end{array}\right)
$$

综合指标为:

$$
\begin{aligned}
& F_{1}=a_{11} x_{1}+a_{21} x_{2}+\cdots+a_{p 1} x_{p} \\
& F_{2}=a_{12} x_{1}+a_{22} x_{2}+\cdots+a_{p 2} x_{2} \\
& \vdots \\
& F_{m}=a_{1 m} x_{1}+a_{2 m} x_{2}+\cdots+a_{p m} x_{m}
\end{aligned}
$$

上式可简写为: $F_{m}=a_{1 i}+a_{2 i}+\cdots+a_{p m} x_{m}(i=1, \cdots, m)$, 并取: $a_{1 i}^{2}+a_{2 i}^{2}+\cdots+a_{p i}^{2}=1$ 。 其中, $x_{m n}$ 为矩阵变量, $a_{m n}$ 为协方差矩阵。满足条件: (1) $F_{i}$ 与 $F_{j}$ 不相关 $(i \neq j ; i, j=1,2, \cdots, m) ;(2) F_{1}$ 是 $x_{1}, x_{2}, \cdots, x_{p}$ 的所有线性函数组合中方差最大 者, 并以此类推。

\section{4 数据来源与处理}

为了确保研究结果的科学性, 碳排放测度将围绕能源消耗与农业生产双方面展开, 具体测算方法及数据来源与处理参照田云等 ${ }^{[25]}$ 的已有做法, 为了控制篇幅在此不做过多 阐述。林木资源蓄积量、农作物播种面积出自《中国农村统计年鉴》，从业劳动力数量由 各地区统计年鉴获取, 三者均以当年实际数值为准; GDP 由《中国统计年鉴》获取, 并 以 2005 年不变价作为基准进行调整。 $R \& D$ 投人比例、环境污染防治投人同样出自《中国 统计年鉴》, 且以该年实际数值为准。资本投人以历年资本存量进行替代, 分析中参照单 豪杰 ${ }^{[26}$ 的研究, 利用永续盘存法进行估算, 并同样以 2005 年作为价格基准年份, 而估算 所需要的数据出自各地区统计年鉴。

\section{2 结果分析}

\section{1 中国碳排放权区域分配及初始空间余额}

首先, 基于相关数据的有效收集, 通过熵值法确定各个指标的权重。结果表明，林 
木蓄积量所占权重最大, 为 $38.93 \%$; 国内生产总值紧随其后排在第二位, 其权重为 $17.40 \%$; 农业播种面积、碳生产力、从业人口依次排在 3 5 位, 所占权重分别为 $16.40 \%$ 、 $13.89 \%$ 和 $13.38 \%$ 。综合来看，以上三类指标中，保障性指标在碳排放权分配过 程中所起作用最大, 公平性指标居中, 而效率性指标影响略小。与此同时, 利用 $\mathrm{k}$-均值 法进行聚类，可将我国 30 个省级行政区划分为 6 个不同区组 ${ }^{2}$ 。接下来，在核算我国碳排 放权总量的基础上明晰 6 大区组的分配比例。结果显示，假定经济增速为 $5.00 \%, 2017-$ 2030 年我国总的碳排放权为 $2119.375 \times 10^{8} \mathrm{t}$; 若经济增速达到 $6.00 \%$, 这一数值则增至 $2262.756 \times 10^{8} \mathrm{t}$ 。同时, 通过式 (9) 计算出人口数量、国内生产总值等 5 个指标的组中 心，而后将各指标权重与其对应的组中心占比相乘，可得第 I、第II、第III、第IV、第 V 和第 VI区组碳排放权的分配比例依次为 $8.92 \%$ 、 $15.00 \% 、 20.63 \% 、 6.37 \%$ 、33.69\% 和 $15.39 \%$ 。在此基础上，基于各省区碳的影子价格差异完成碳排放权的最终分配。考虑到 篇幅有限, 研究将重点探讨乐观情形（即经济年均增速为 $6.00 \%$ ）下各地区在 2017 年的 碳排放权分配状况。测算结果显示，该年我国碳排放权分配总额为 $134.900 \times 10^{8} \mathrm{t}$ ，其中 云南、四川、黑龙江依次占据前 3 位, 其配额均超过了 $10 \times 10^{8} \mathrm{t}$, 分别为 $14.209 \times 10^{8} \mathrm{t}$ 、 $13.694 \times 10^{8} \mathrm{t}$ 和 $11.704 \times 10^{8} \mathrm{t}$ 。与此对应, 宁夏碳排放权配额最少, 仅为 $0.382 \times 10^{8} \mathrm{t}$, 山 西、新疆依次排在倒数二、三位, 分别为 $0.591 \times 10^{8} \mathrm{t} 、 0.669 \times 10^{8} \mathrm{t}$ 。最后, 将各地区 2017 年理论碳排放权分配额与其实际碳排量相减, 所得差额即为 30 个地区在该年的碳排 放权初始空间余额，具体如表 3 所示。

由表 3 可知，目前全国有 14 个地区表现出盈余特征。其中，云南碳排放权初始空间 余额最高, 达到了 $11.751 \times 10^{8} \mathrm{t}$; 四川、黑龙江、北京紧随其后, 各自余额均在 $7 \times 10^{8} \mathrm{t}$ 以 上, 分别为 $10.143 \times 10^{8} \mathrm{t} 、 7.646 \times 10^{8} \mathrm{t} 、 7.080 \times 10^{8} \mathrm{t}$; 通过比较发现，上述 4 地碳排放权初 始空间余额要明显高于其他地区, 可归为 “充分盈余” 地区。河南、江西、湖北、广 西、上海、吉林等 6 地依次排在 $5 \sim 10$ 位, 各自余额介于 $1 \times 10^{8} \sim 3 \times 10^{8} \mathrm{t}$ 之间, 可归为 “中 度盈余” 地区。除此之外, 海南、青海、广东、江苏等 4 地也表现出了一定空间盈余特 征, 但余额数量较低, 均低于 $1 \times 10^{8} \mathrm{t}$, 可归为 “略微盈余” 地区。从总体区域分布来 看，东、中、西部均有涉及，根据成因差异可大致分为三类：（1）以京、沪、赣、桂、 川、滇等 6 地为代表的 “低排放、高配额” 地区, 这些地区或自身能耗水平较低、或能 源利用结构相对合理, 客观上促使各自碳排放量处于较低水平。（2）以吉、琼、青等 3 地 为代表的 “低排放、低配额” 地区, 各自相对较小的经济体量一定程度上抑制了对能源 的消耗，进而使其碳排放量处于较低水平。（3）以黑、苏、豫、鄂、粤等 5 地为代表的 “高排放、高配额” 地区，各地二、三产业能源消耗数量巨大，且均为农业生产大省，由 此导致其碳排放量居高不下。

其他 16 个地区的碳排放权初始空间余额均表现出了一定程度的欠缺，而根据各自的 欠缺程度可将其划分为三类：（1）轻度欠缺地区，即碳排放权初始空间余额为 $-1 \times 10^{8} \sim 0 \mathrm{t}$, 包含浙江、安徽、福建、重庆等 4 地。其中浙、皖二地属于典型的 “高排放、高配额” 地区, 其理论配额为当前碳排放量的 $90 \%$ 甚至以上, 所面临的减排压力可能相对较小;

(2) 其中, 第I区组仅包含北京、上海 2市; 第II区组包含河北、浙江、安徽、湖北、湖南 5 省; 第III区组包含江 苏、山东、河南、广东 4省; 第IV区组包含天津、山西、海南、重庆、贵州、甘肃、青海、宁夏、新疆 5 省 2 市 2 区; 第V区组包含内蒙古、黑龙江、四川、云南 3 省 1 区; 第VI区组包含辽宁、吉林、福建、江西、广西、陕西 5 省 1区。 
表 32017 年我国 30 个省级行政区碳排放量、碳排放权分配额及其初始余额

Table 3 Carbon emissions, allocation of carbon emission rights and their initial balances in 30 provinces of China

\begin{tabular}{|c|c|c|c|c|c|c|c|c|c|c|}
\hline \multicolumn{2}{|c|}{ 地区 } & \multicolumn{3}{|c|}{ 碳排放权分配额 } & \multicolumn{3}{|c|}{ 碳排放量 } & \multicolumn{3}{|c|}{ 碳排放权初始空间余额 } \\
\hline 组别 & 地区 & 数量 $/ 10^{8} \mathrm{t}$ & 占比 $/ \%$ & 排名 & 数量 $/ 10^{8} \mathrm{t}$ & 占比 $/ \%$ & 排名 & 数量 $/ 10^{8} \mathrm{t}$ & 排名 & 类型 \\
\hline \multirow{2}{*}{$\begin{array}{l}\text { I 区组 } \\
8.92 \%\end{array}$} & 北京 & 7.885 & 5.85 & 6 & 0.805 & 0.60 & 28 & 7.080 & 4 & 充分盈余 \\
\hline & 上海 & 4.143 & 3.07 & 13 & 2.612 & 1.94 & 22 & 1.531 & 9 & 中度盈余 \\
\hline \multirow{5}{*}{$\begin{array}{l}\text { II区组 } \\
15.00 \%\end{array}$} & 河北 & 3.835 & 2.84 & 16 & 8.747 & 6.48 & 3 & -4.912 & 27 & 重度欠缺 \\
\hline & 浙江 & 4.050 & 3.00 & 14 & 4.586 & 3.40 & 11 & -0.535 & 17 & 轻度欠缺 \\
\hline & 安徽 & 4.514 & 3.35 & 12 & 4.544 & 3.37 & 12 & -0.030 & 15 & 轻度欠缺 \\
\hline & 湖北 & 6.098 & 4.52 & 8 & 4.163 & 3.09 & 13 & 1.935 & 7 & 中度盈余 \\
\hline & 湖南 & 1.738 & 1.29 & 21 & 3.995 & 2.96 & 15 & -2.258 & 23 & 中度欠缺 \\
\hline \multirow{4}{*}{$\begin{array}{l}\text { III区组 } \\
20.63 \%\end{array}$} & 江苏 & 8.765 & 6.50 & 5 & 8.667 & 6.42 & 4 & 0.098 & 14 & 略微盈余 \\
\hline & 山东 & 2.819 & 2.09 & 18 & 14.465 & 10.72 & 1 & -11.646 & 30 & 重度欠缺 \\
\hline & 河南 & 9.139 & 6.77 & 4 & 6.302 & 4.67 & 8 & 2.837 & 5 & 中度盈余 \\
\hline & 广东 & 7.109 & 5.27 & 7 & 6.698 & 4.97 & 7 & 0.410 & 13 & 略微盈余 \\
\hline \multirow{9}{*}{$\begin{array}{l}\text { IV区组 } \\
6.37 \%\end{array}$} & 天津 & 0.693 & 0.51 & 27 & 1.733 & 1.28 & 26 & -1.040 & 19 & 中度欠缺 \\
\hline & 山西 & 0.591 & 0.44 & 29 & 9.118 & 6.76 & 2 & -8.528 & 29 & 重度欠缺 \\
\hline & 海南 & 1.619 & 1.20 & 22 & 0.695 & 0.52 & 29 & 0.924 & 11 & 略微盈余 \\
\hline & 重庆 & 1.210 & 0.90 & 24 & 1.614 & 1.20 & 27 & -0.404 & 16 & 轻度欠缺 \\
\hline & 贵州 & 0.900 & 0.67 & 26 & 3.106 & 2.30 & 17 & -2.206 & 22 & 中度欠缺 \\
\hline & 甘肃 & 1.058 & 0.78 & 25 & 2.172 & 1.61 & 25 & -1.114 & 20 & 中度欠缺 \\
\hline & 青海 & 1.476 & 1.09 & 23 & 0.642 & 0.48 & 30 & 0.834 & 12 & 略微盈余 \\
\hline & 宁夏 & 0.382 & 0.28 & 30 & 2.570 & 1.90 & 23 & -2.187 & 21 & 中度欠缺 \\
\hline & 新疆 & 0.669 & 0.50 & 28 & 5.641 & 4.18 & 9 & -4.972 & 28 & 重度欠缺 \\
\hline \multirow{4}{*}{$\begin{array}{l}\text { V区组 } \\
33.69 \%\end{array}$} & 内蒙古 & 5.838 & 4.33 & 9 & 8.636 & 6.40 & 5 & -2.798 & 25 & 中度欠缺 \\
\hline & 黑龙江 & 11.704 & 8.68 & 3 & 4.058 & 3.01 & 14 & 7.646 & 3 & 充分盈余 \\
\hline & 四川 & 13.694 & 10.15 & 2 & 3.551 & 2.63 & 16 & 10.143 & 2 & 充分盈余 \\
\hline & 云南 & 14.209 & 10.53 & 1 & 2.458 & 1.82 & 24 & 11.751 & 1 & 充分盈余 \\
\hline \multirow{6}{*}{$\begin{array}{l}\text { VI区组 } \\
15.39 \%\end{array}$} & 辽宁 & 3.008 & 2.23 & 17 & 7.289 & 5.40 & 6 & -4.280 & 26 & 重度欠缺 \\
\hline & 吉林 & 3.921 & 2.91 & 15 & 2.650 & 1.96 & 21 & 1.271 & 10 & 中度盈余 \\
\hline & 福建 & 1.994 & 1.48 & 20 & 2.821 & 2.09 & 18 & -0.827 & 18 & 轻度欠缺 \\
\hline & 江西 & 4.855 & 3.60 & 10 & 2.752 & 2.04 & 20 & 2.103 & 6 & 中度盈余 \\
\hline & 广西 & 4.515 & 3.35 & 11 & 2.790 & 2.07 & 19 & 1.725 & 8 & 中度盈余 \\
\hline & 陕西 & 2.470 & 1.83 & 19 & 5.020 & 3.72 & 10 & -2.550 & 24 & 中度欠缺 \\
\hline
\end{tabular}

闽、渝二地碳排放权配额与当前碳排放量均属于较低水平，经济发展层次在全国居于中 等水平，各自减排工作均面临一定压力。（2）中度欠缺地区，即碳排放权初始空间余额 为 $-3 \times 10^{8} \sim-1 \times 10^{8} \mathrm{t}$, 包含天津、内蒙古、湖南、贵州、陕西、甘肃、宁夏等 7 地, 除天 津外均为我国中西部省区。其中, 内蒙古、陕西属于产煤大省（自治区）, 其能源利用结 构相对单一，客观导致各自碳排放量处于较高水平；除此之外的其他地区均表现出 “低 排放、低配额” 特征，且前者数量要明显少于后者，各自碳排放权理论配额均不及其 碳排放量的 50\% , 面临较大减排压力。（3）重度欠缺地区，即碳排放权初始空间余额 低于 $-3 \times 10^{8} \mathrm{t}$, 包含河北、山西、辽宁、山东、新疆等 5 地，都呈现出较为明显的 “高排 
放、低配额” 特征, 从目前境况来看均面临极为严重的碳排放赤字, 高耗能源的广泛利 用是导致其碳排放量居高不下的关键动因，而各自林木资源蓄积量的相对欠缺又极大制 约了其碳排放权的分配。

\section{2 碳排放权欠缺地区碳减排潜力综合评估}

基于前文所构建的指标评价体系，完成对碳排放权欠缺地区碳减排潜力的综合评 估, 相关结果如图 1 所示。从图中不难发现, 浙江、天津、山东等 3 地的综合评分要明显 高于其他 13 个地区，表明它们减排潜力较大，未来所面临的碳减排压力相对较小，就区 域分布而言均位于我国东部。福建、重庆、安徽、湖南、辽宁、陕西、河北等 7 地依次 排在 4 10 位, 评分介于 55 80 之间, 这些地区的减排目标实现潜力在 16 个碳排权欠缺省 份中处于居中水平, 主要分布于我国中部。甘肃、内蒙古、贵州、山西、宁夏、新疆等 6 地综合评分均在 45 以下，依次排在 11 16位，上述地区所呈现出的碳减排潜力相对较 小, 其中除山西之外均为我国西部省 (自治区)。进一步分析揭示, 各地区碳减排潜力与 其碳排放权欠缺量虽表现出了一定趋同性但并非完全一致，具体表现为：减排潜力居于 前列的浙、津、鲁等 3 地分属碳排放权轻度、中度和重度欠缺地区; 减排潜力处于居中 水平的闽、渝、皖等 3 地属于碳排权轻度欠缺地区，其他 4 地则属于中度或者重度欠缺地 区; 而减排潜力较小的甘、内蒙古、黔等 6 地碳排权欠缺数量同样差异较大, 重度、中 度均有涉及。

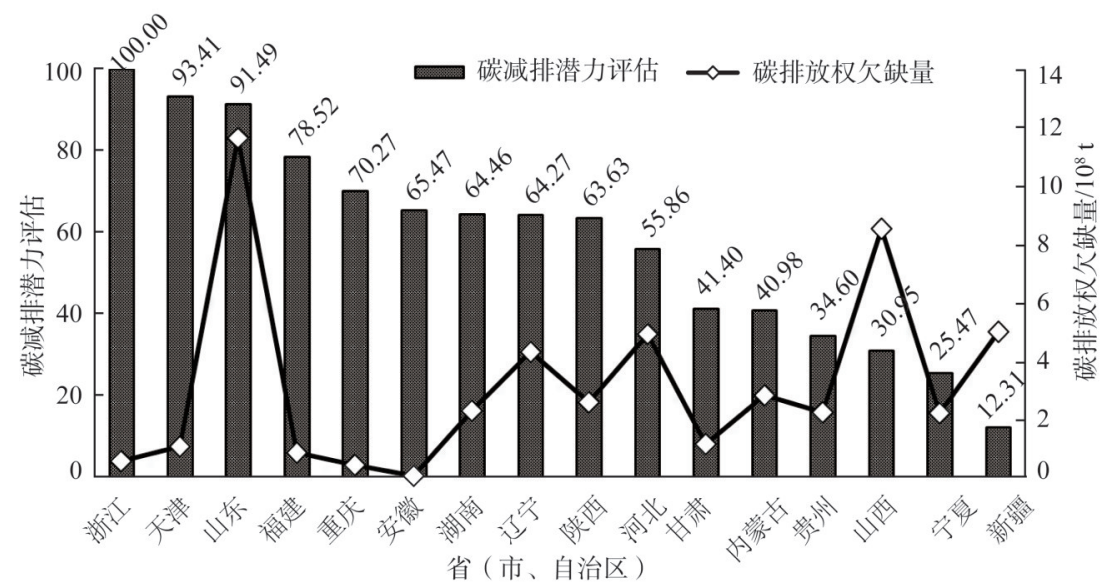

注: 为了便于比较, 将分值最高者折算为 100 , 其他地区以此类推。

图 1 碳排放权欠缺省区减排潜力综合评估结果

Fig. 1 Results of comprehensive assessment on emission reduction potential of provinces with a lack of carbon emission rights

\section{3 结论与启示}

通过本文分析，主要得出以下几方面结论：

（1）我国 30 个省（市、自治区）碳排放权分配数额差异较大，其中云南、四川、黑 龙江依次占据前 3 位, 其配额均超过了 $10 \times 10^{8} \mathrm{t}$, 分别为 $14.209 \times 10^{8} \mathrm{t} 、 13.694 \times 10^{8} \mathrm{t}$ 、 $11.704 \times 10^{8} \mathrm{t}$ 。与此对应, 宁夏配额最少, 仅为 $0.382 \times 10^{8} \mathrm{t}$, 山西、新疆依次排在倒数 二、三位，分别为 $0.591 \times 10^{8} \mathrm{t} 、 0.669 \times 10^{8} \mathrm{t}$ 。 
（2）14个地区的碳排放权初始空间余额表现为盈余状态，其中以云南最高，根据原 因差异可大致分为 “低排放、高配额” “低排放、低配额” 以及 “高排放、高配额” 等三 类不同地区。其他 16 个地区均表现出了一定程度的欠缺，结合数值差异可划分为以江苏 等 4 地为代表的轻度欠缺地区，以天津等 7 地为代表的中度欠缺地区，以及以辽宁等 5 地 为代表的重度欠缺地区。

（3）在 16 个碳排放权欠缺地区中，浙江、天津、山东等 3 地所具备的碳减排潜力要 明显高于其他地区，处于领先水平；福建、重庆、安徽等 7 地的减排目标实现潜力处于 居中水平; 而甘肃、内蒙古、贵州等 6 地所呈现出的碳减排潜力相对较小。进一步分析 表明，各地区碳减排潜力与其碳排放权欠缺量之间虽表现出了一定趋同性但并非完全 一致。

与已有研究 ${ }^{[23,27]}$ 相比，本文研究视野得到了一定拓展，比如碳排权区域分配指标体系 的构建不仅涉及到社会经济指标，还兼顾生态效益指标，切实保证了指标选择的全面性 与合理性；又如除了常规的碳排放权区域分配与初始空间余额测度研究之外，还综合评 估了碳排放权欠缺地区的减排潜力, 由此增强了本文的分析深度。研究揭示, 我国各省 （市、自治区）碳排放权分配差异较大，且有高达 16 个地区初始空间余额存在一定程度 的不足。为了使这种不利局面能得到有效改善, 可以考虑从以下几方面着手：一是合理 制定总体规划，强化制度保障与政策支持。二是逐步完善碳排放权交易机制，通过跨省 权限交易实现区域协同减排。三是全面实施动态评估机制，适时调整碳排放权省域分配 模式。四是加大低碳理念的宣传与推广力度，鼓励节能减排技术的广泛运用。

\section{参考文献(References):}

[1] SATHAYE J, MONAHAN P, SANSTAD A. Costs of reducing carbon emissions from the energy sector: A comparison of China, India, and Brazil. Ambio, 1996, 25(4): 262-266.

[2] 陈文颖, 吴宗金金. 气候变化的历史责任与碳排放限额分配. 中国环境科学, 1998, (6): 2-6. [CHEN W Y, WU Z X. Historical responsibility for climate change and carbon emission right allocation. China Environmental Science, 1998, (6): 2-6.]

[3] ZHANG Z X. Decoupling China's carbon emissions increase from economic growth: An economic analysis and policy implications. World Development, 2000, 28, 4: 739-752.

[4] 潘家华. 发展分析的概念构架与经验数据: 以对碳排放空间的需求为例. 中国社会科学, 2002, (6): 15-25, 204. [PAN J H. A conceptual framework for understanding human development potential: With empirical analysis of global demand for carbon emissions. Social Sciences in China, 2002, (6): 15-25, 204.]

[5] 胡振, 王玥, 何晶晶, 等. 西部城镇家庭能源消费及其碳排放的区域特征研究: 基于中国家庭追踪调查的调研数据. 干旱区资源与环境, 2019, 33(4): 1-8. [HU Z, WANG Y, HE J J, et al. Characteristics of urban household energy consumption and carbon emissions in Western China: Evidence from China Family Panel Studies (CFPS). Journal of Arid Land Resources and Environment, 2019, 33(4): 1-8.]

[6] 彭水军, 张文城, 孙传旺. 中国生产侧和消费侧碳排放量测算及影响因素研究. 经济研究, 2015, 50(1): 168-182. [PENG S J, ZHANG W C, SUN C W. China's production-based and consumption-based carbon emissions and their determinants. Economic Research Journal, 2015, 50(1): 168-182.]

[7] 王锋, 吴丽华, 杨超. 中国经济发展中碳排放增长的驱动因素研究. 经济研究, 2010, 45(2): 123-136. [WANG F, WU L H, YANG C. Driving factors for growth of carbon dioxide emissions during economic development in China. Economic Research Journal, 2010, 45(2): 123-136.]

[8] 许广月, 宋德勇. 中国碳排放环境库兹涅茨曲线的实证研究: 基于省域面板数据. 中国工业经济, 2010, (5): 37-47. 
[XU G Y, SONG D Y. An empirical study of the Environmental Kuznets Curve for China's carbon emissions: Based on provincial panel data. China Industrial Economics, 2010, (5): 37-47.]

[9] LI Y, HEWITT C N. The effect of trade between China and the UK on national and global carbon dioxide emissions. Energy Policy, 2008, 36(6): 1907-1914.

[10] 黄芯, 王铮, 钟章奇, 等. 区域贸易隐含碳排放和 $\mathrm{SO}_{2}$ 排放的投人产出分析: 以江苏为例. 自然资源学报, 2017, 32(5): 854-863. [HUANG R, WANG Z, ZHONG Z Q, et al. Input-output analysis of embodied carbon emissions and $\mathrm{SO}_{2}$ emissions in regional trade: A case study of Jiangsu. Journal of Natural Resources, 2017, 32(5): 854-863.]

[11] DHAKAL S. Urban energy use and carbon emissions from cities in China and policy implications. Energy Policy, 2009, 37(11): 4208-4219.

[12] TIAN Y, ZHANG J B, HE Y Y. Research on spatial-temporal driving factor of agricultural carbon emissions in China. Journal of Integrative Agriculture, 2014, 6: 1393-1403.

[13] CHANG C C. A multivariate causality test of carbon dioxide emissions, energy consumption and economic growth in China. Applied Energy, 2010, 87(11): 3533-3537.

[14] LI F, DONG S C, LI X, et al. Energy consumption-economic growth relationship and carbon dioxide emissions in China. Energy Policy, 2011, 39(2): 568-574.

[15] 李锴, 齐绍洲. 贸易开放、经济增长与中国二氧化碳排放. 经济研究, 2011, 46(11): 60-72, 102. [LI K, QI S Z. Trade openness, economic growth and carbon dioxide emission in China. Economic Research Journal, 2011, 46(11): 60-72, 102.]

[16] WANG K, WEI Y M. China's regional industrial energy efficiency and carbon emissions abatement costs. Applied Energy, 2014, 136(s1): 617-631.

[17] CUI L B, FAN Y, ZHU L, et al. How will the emissions trading scheme save cost for achieving China's 2020 carbon intensity reduction target?. Applied Energy, 2014, 136(12): 1043-1052.

[18] 周迪, 王雪芹. 中国碳排放效率与产业结构升级的耦合度及耦合路径. 自然资源学报, 2019, 34(11): 2305-2316. [ZHOU D, WANG X Q. Research on coupling degree and coupling path between China's carbon emission efficiency and industrial structure upgrade. Journal of Natural Resources, 2019, 34(11): 2305-2316.]

[19] 林伯强, 孙传旺. 如何在保障中国经济增长前提下完成碳减排目标. 中国社会科学, 2011, (1): 64-76, 221. [LIN B Q, SUN C W. How can China achieve its carbon emission reduction target while sustaining economic growth. Social Sciences in China, 2011, (1): 64-76, 221.]

[20] 涂正革. 中国的碳减排路径与战略选择: 基于八大行业部门碳排放量的指数分解分析. 中国社会科学, 2012, (3): 78-94, 206-207. [TU Z G. Strategic measures to reduce China's carbon emissions: Based on index decomposition analysis of carbon emission in eight industries. Social Sciences in China, 2012, (3): 78-94, 206-207.]

[21] JIANG J J, YE B, XIE D J, et al. Provincial-level carbon emission drivers and emission reduction strategies in China: combining multi-layer LMDI decomposition with hierarchical clustering. Journal of Cleaner Production, 2017, 169(12): 178-190.

[22] 黄志平. 碳排放权交易有利于碳减排吗? 基于双重差分法的研究. 干旱区资源与环境, 2018, 32(9): 36-40. [HUANG Z P. Does the carbon emission trading scheme promote carbon mitigation?. Journal of Arid Land Resources and Environment, 2018, 32(9): 36-40.]

[23] 王勇, 程瑜, 杨光春, 等. 2020 和 2030 年碳强度目标约束下中国碳排放权的省区分解. 中国环境科学, 2018, 38(8): 3180-3188. [WANG Y, CHENG Y, YANG G C, al et. Provincial decomposition of China's carbon emission rights under the constraint of 2020 and 2030 carbon intensity targets. China Environmental Science, 2018, 38(8): 3180-3188.]

[24] 周迪, 郑楚鹏, 华诗润, 等. 公平与效率协调视角下的中国碳减排潜力与路径. 自然资源学报, 2019, 34(1): 80-91. [ZHOU D, ZHENG C P, HUA S R, et al. The potentialities and paths of China's carbon emission reduction based on the coordination of fairness and efficiency. Journal of Natural Resources, 2019, 34(1): 80-91.]

[25] 田云, 陈池波. 中国碳减排成效评估、后进地区识别与路径优化. 经济管理, 2019, (6): 23-37. [TIAN Y, CHEN C B. Effectiveness evaluation of carbon emission reduction in China, identification of backward areas and path optimization. 
Business Management Journal, 2019, (6): 23-37.]

[26] 单豪杰. 中国资本存量 K 的在估算: 1952-2006年. 数量经济与技术经济研究, 2008, 25(10): 17-31. [SHAN H J. Reestimating the capital stock of China: 1952-2006. The Journal of Quantitative \& Technical Economics, 2008, 25(10): 1731.]

[27] 王慧慧, 刘恒辰, 何霄嘉, 等. 基于代际公平的碳排放权分配研究. 中国环境科学, 2016, 36(6): 1895-1904. [WANG H H, LIU H C, HE X J, et al. Allocation of carbon emissions right based on the intergenerational equity. China Environmental Science, 2016, 36(6): 1895-1904.]

\title{
Provincial distribution of China's carbon emission rights and assessment of its emission reduction potential under the Paris Agreement
}

\author{
TIAN Yun, LIN Zi-juan \\ (School of Business Administration, Zhongnan University of Economics and Law, Wuhan 430073, China)
}

\begin{abstract}
In this paper, the provincial distribution is completed by constructing a regional distribution model of carbon emission rights. On this basis, the initial space balance is clarified by comparing with the actual carbon emissions in various places. Then, the potential of carbon emission reduction in regions lacking carbon emission rights is comprehensively evaluated. The results show that: (1) The distribution of carbon emission rights in 30 provinces of China is quite different, among which Yunnan has the highest quota, accounting for $10.53 \%$, while Ningxia has the least quota, accounting for only $0.28 \%$. (2) The initial space balance of carbon emission rights in 14 provinces of China shows a surplus state, which can be divided into three types according to the difference of causes, namely "low emission, high quota", "low emission, low quota" and "high emission, high quota". All the other 16 provinces show some degree of deficiency. Combined with the numerical differences, they can be identified into three types: 4 provinces with slight deficiency represented by Jiangsu, 7 with moderate deficiency represented by Tianjin, and 5 with severe deficiency represented by Liaoning. (3) Currently, Zhejiang, Tianjin and Shandong have significantly higher carbon emission reduction potential than other regions, while the carbon emission reduction potential level of each region shows certain convergence but is not completely consistent with a lack of carbon emission rights.
\end{abstract}

Keywords: carbon emissions; agricultural carbon emissions; carbon emission rights; provincial distribution; emission reduction potential 